\title{
Rapid Application Temporary Tattoos for Medical Moulage: From Development to Testing and Commercialization
}

\author{
Elizabeth N. Weissbrod, Joseph O. Lopreiato, Mark W. Bowyer, Danielle A. Simms, \\ and Eric M. Singdahlsen
}

\begin{abstract}
Military medical education and training often utilize theatrical makeup, or moulage, to simulate injuries or pathologies. Traditional methods of moulage application are incredibly realistic when expertly applied. However, moulage can be expensive in terms of supplies, manpower, and time. We proposed that by creating a library of illustrations for use with temporary tattoos, the overall cost of moulage could decrease with little to no impact on training goals and objectives. The development, detailed testing and plans for commercialization are outlined herein.
\end{abstract}

Keywords: simulation, moulage, temporary tattoos, military medicine, medical illustration, education

Disclaimers: The opinions and assertions expressed herein are those of the author(s) and do not necessarily reflect the official policy or position of the Uniformed Services University, the Department of Defense, or the Henry M. Jackson Foundation for the Advancement of Military Medicine.

No authors, nor family members, have a financial interest in any commercial product, service, or organization providing financial support for this research.

\section{Introduction}

Simulation is a validated method to improve individual provider and medical team competencies by replicating real-world scenarios (Deering et al. 2012). Simulation effectively prepares medical personnel for the procedures and skills they must accurately perform to save lives (McGaghie et al. 2011; Meguerdichian, Heiner, and Younggren 2012). Medical simulation is utilized in many different environments and can be adapted to different skill levels and specialties.

The versatility of simulation is especially important for those in the Military Health System (MHS). MHS service members operate in locations all over the globe and need to be prepared to treat any wound presented with the resources available in that environment (Deering et al. 2012). Such a wide range of training, learning objectives, and skill level demands an adaptable learning platform. In the MHS, training exercises often combine multiple simulation methods aimed at achieving this (Goolsby and Deering 2013). The training scenarios may only include one standardized patient (SP) for a basic clinic encounter, or it could involve upwards of 50 patients, combined with manikins, for a mass casualty exercise. (Figure 1)

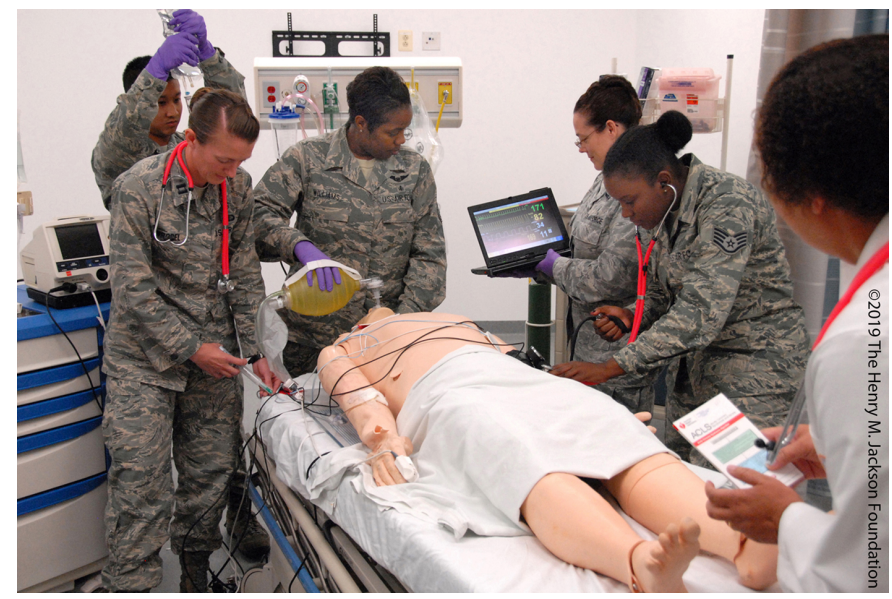

Figure 1. A photo of a simulated patient scenario in progress. This took place in the Val G. Hemming Simulation Center (VGHSC) Hybrid Lab. Here, a manikin is shown as the patient and the team is working as a unit under leadership of a head

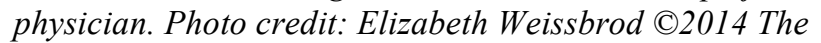
Henry M. Jackson Foundation

Complex training scenarios create opportunities to improve the educational value for learners with the use of moulage (Gormley et al. 2013; Howard 2018; Merica 2012). Moulage is, "the art of creating lifelike injuries to assist in providing shock desensitization, realism, and training techniques..." (Merica 2012). Learning objectives for a simulation scenario dictate if, when, or how moulage needs to be applied.

Application techniques are as numerous as potential injuries. Traditional techniques include stage makeup, powders, waxes, latex, glues, and Gelefects (Merica 2012). Sometimes silicone, or other polymer, prosthetics are used for intricate injuries.

(Figure 2) Practices in moulage application vary widely. When applied correctly, moulage is very effective in creating an immersive environment for learners (Mills et al. 2018; Petersen et al. 2017; Swan 2013). Depending on the complexity of the desired wound, and the necessary realism, a single wound can take longer than 60 minutes to simulate. For example, if a scenario called for a patient to present with severe blast injuries (i.e. open fractures, burns, lacerations, shrapnel wounds, amputation), the moulage required would take much longer than if the patient were presenting with bruises from a fall. Likewise, the number of iterations in which a scenario will run must be taken into account. If the moulage technique chosen is not durable (e.g. wax), the quality will deteriorate with each 
iteration. The techniques chosen should support the learning objectives of the course with injuries that are realistically depicted, anatomically accurate, and time and cost efficient.

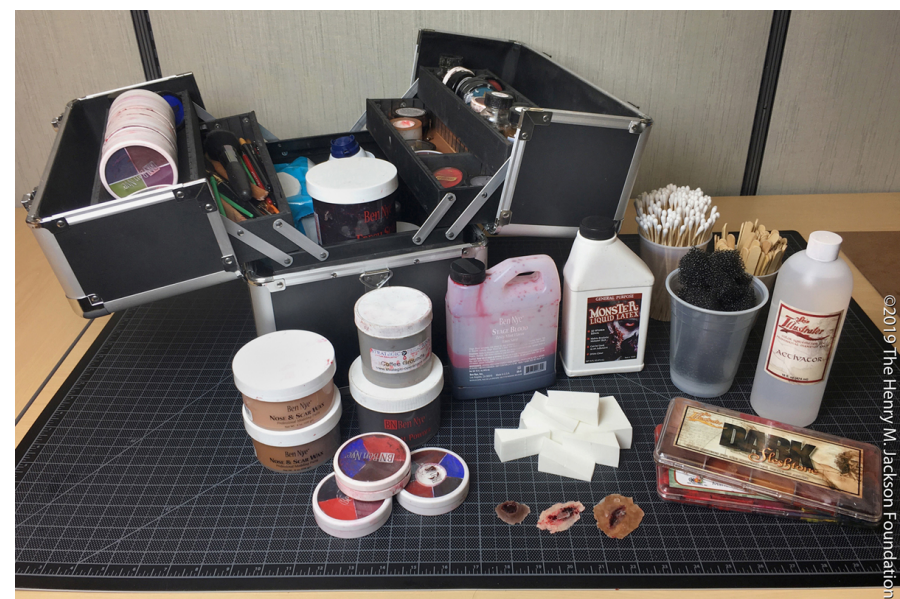

Figure 2. An example of contents that can be found for use in a traditional moulage kit. Photo credit: Elizabeth Weissbrod (C)2019 The Henry M. Jackson Foundation

We have developed and field tested a temporary tattoo moulage technique that can save time, personnel, and overall cost for medical training simulations. These tattoos can be applied quickly to human actors or mannequins, requiring minimal training and few supplies. (Figure 3).

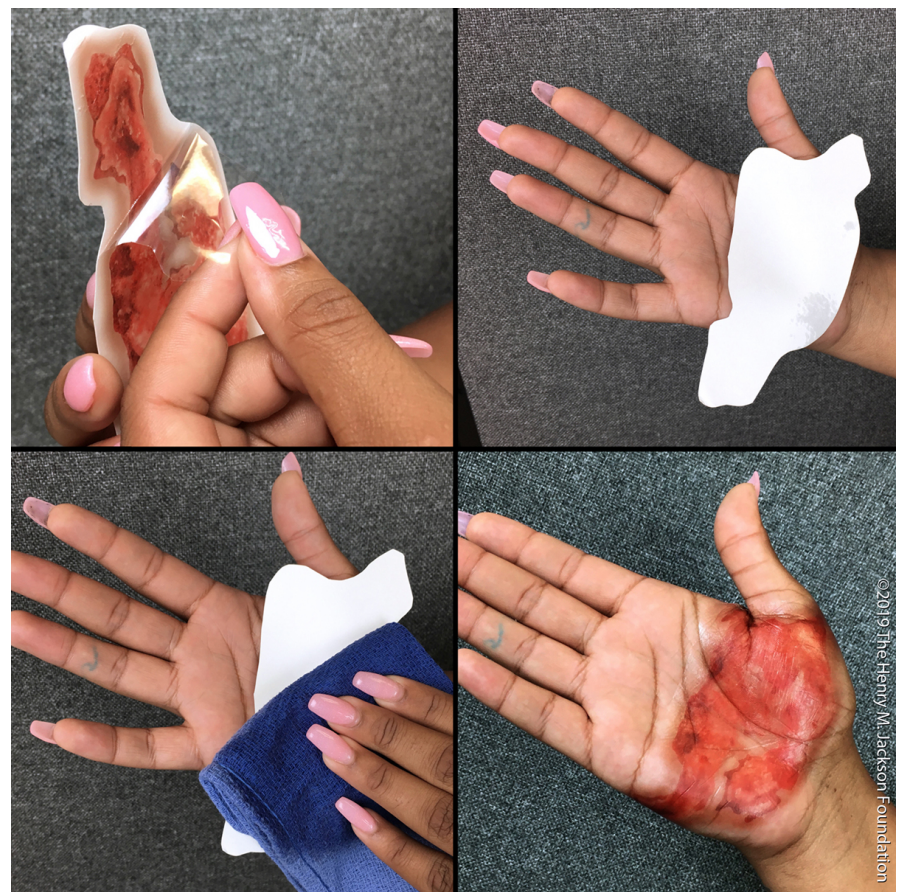

Figure 3. Photo sequence showing how to apply the temporary tattoos: peel off the clear layer, stick the tattoo to the clean desired area, wet the paper backing, and slide off the paper backing. Photo credit: Elizabeth Weissbrod (C2019 The Henry M. Jackson Foundation

\section{Methodology}

\section{History of the Val G. Hemming Simulation Center} Temporary Tattoo Moulage Program

The concept of temporary tattoos moulage evolved over time. While working with the National Museum of Health and Medicine (NMHM), we volunteered to provide moulage for the "Anatomy of Sports" event. (Figure 4) This annual event recruits medical illustrators to physically paint on the bodies of local athletes so museum visitors can learn about the anatomical relationships of movement to that of the musculoskeletal system.

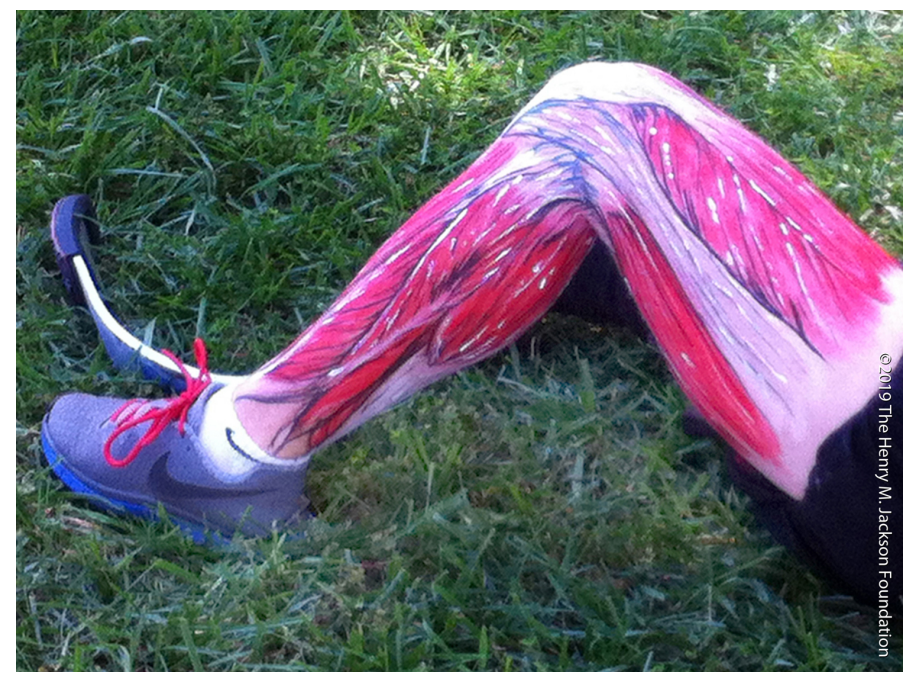

Figure 4. The thigh and leg muscles painted on to the skin of a wounded warrior who participates in the World Class Athlete Program and the Invictus Games during a NMHM "Anatomy of Sports" event. Photo credit: Elizabeth Weissbrod (C)2015 The Henry M. Jackson Foundation

This visual approach to teaching was then applied in a firstyear medical student course at the Val G. Hemming Simulation Center (VGHSC) of the Uniformed Services University (USU). During the fundamentals of physical examination course, the students learn how to do a basic head-to-toe physical exam on a simulated patient. These learners have not yet completed their human anatomy dissection course and may fail to connect surface anatomy to underlying anatomical structures of clinical importance. To help learners make that connection, we began providing a student model with a deep anatomical structure of clinical relevance painted on their skin. For example, if the students needed to palpate the thyroid, a thyroid would be painted on one student per group. While we did not formally evaluate this initial use of moulage body art, the informal feedback was overwhelmingly positive. Instructors increasingly requested the use of body art and these requests overwhelmed the available illustration staff.

We then discovered that commercially available temporary tattoo paper could be utilized to rapidly apply illustrations of the required underlying anatomical structures for the physical examination course. (Figure 5) The course instructors reported that the thyroid, heart, lungs (with lobes delineated), spleen, liver, and kidneys were most useful. Medical illustrations, 
created at the VGHSC, were repurposed or created for use as temporary tattoos.

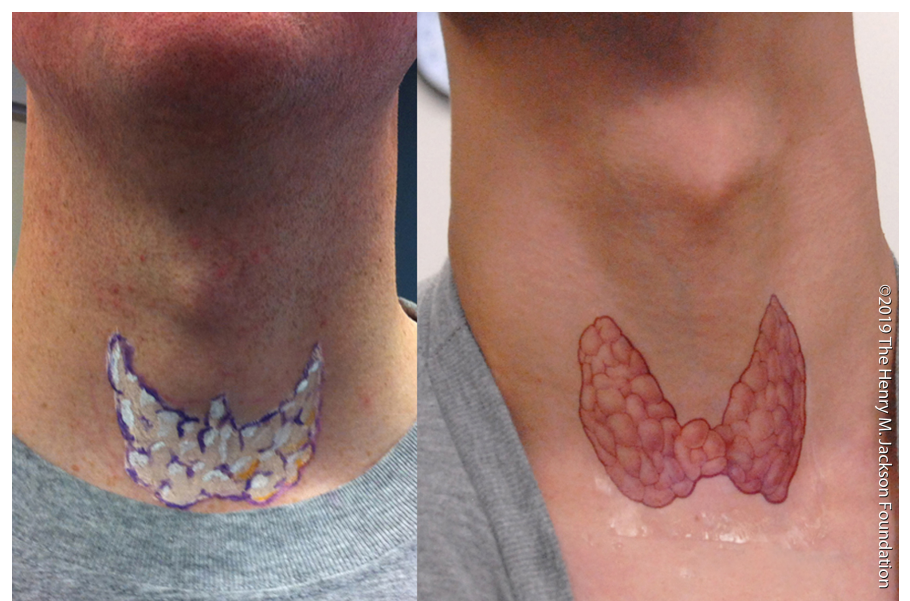

Figure 5. Photos of a thyroid painted onto a medical student (left) versus a temporary tattoo of a thyroid applied to a medical student (right). Photo credit: Elizabeth Weissbrod (C)2014 The Henry M. Jackson Foundation

The success of the anatomy temporary tattoos led us to experiment with using the tattoos for moulage purposes. At first, tattoos were used with injuries difficult to mimic with traditional moulage techniques, such as burns. One burn illustration was created, tested, and achieved a degree of realism. However, we quickly realized that one burn illustration would not be enough. Multiple variants of each type of injury and pathology would be needed.

We used a photographic library of real-world injuries sustained by military and civilian personnel in Iraq and in the Washington DC region for reference when illustrating. Dr. Mark Bowyer, a trauma surgeon from USU, took these photos, omitting all personally identifiable information. A benefit of using trauma photos as reference is that the injuries were depicted prior to being cleaned by medical personnel. Also, the injuries illustrated are more representative of what military personnel may encounter throughout their careers.

From this library, we created illustrations digitally using Adobe Photoshop and Illustrator. Sketching and full color rendering were completed in Photoshop, using multiple brushes, textures, layer effects, and filters to gain desired visual effects. Graphic elements were created in Illustrator.

The Henry M. Jackson Foundation for the Advancement of Military Medicine (HJF) reviewed and submitted each illustration to the U.S. Copyright Office for registration. All artwork was submitted as original illustrations or as derivatives of the original works.

Initially, we grouped each illustration by injury type (laceration, abrasion, bruises, etc.) or by specific injuries defined in the Tactical Combat Casualty Course (TCCC) and the American College of Surgeons' Advance Trauma Life Support (ATLS) course. ATLS uses a standard set of simulated patient scenarios for learning and testing; grouping the illustrated injuries for each simulated patient provided several benefits: the injuries were standardized, each learner encountered the exact same injury, and the course-required moulage could be rapidly applied. Additionally, moulage placement diagrams were created, indicating where each type of tattoo should be placed. (Figure 6)

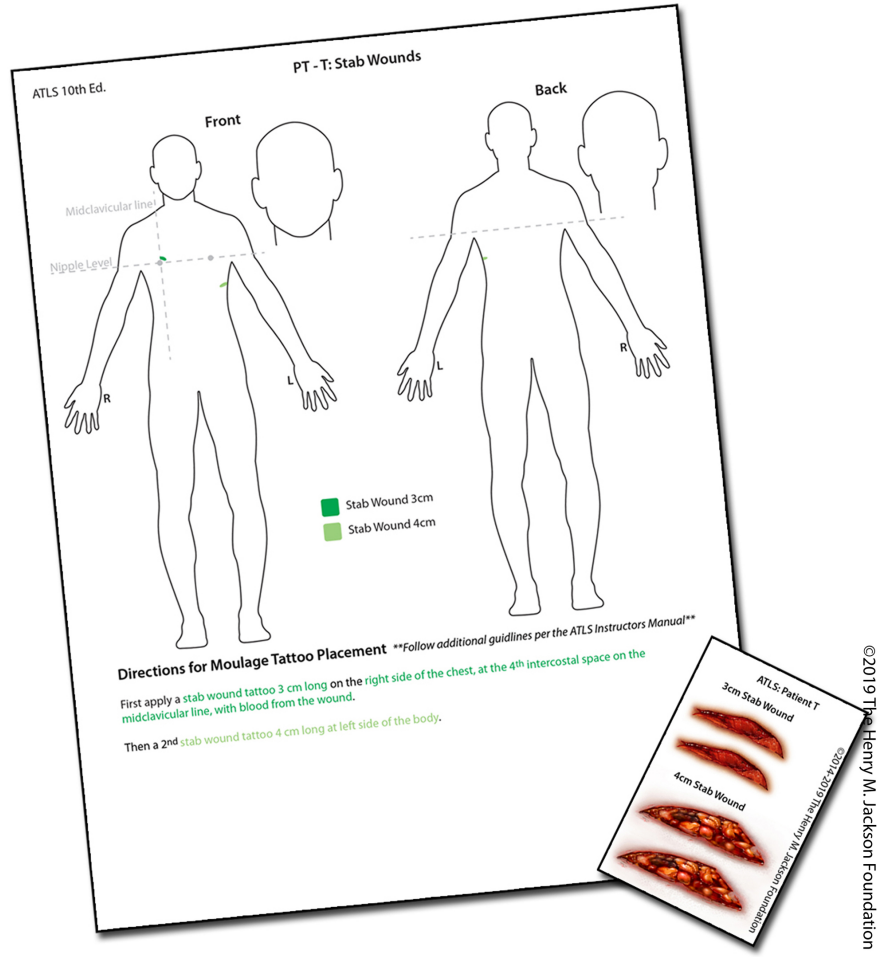

Figure 6. An example of ATLS Patient " $T$ " moulage tattoos and placement diagram. (C2019 The Henry M. Jackson Foundation

As the project progressed, we would occasionally get requests for tattoos of other types of injuries and packages to support other courses, such as Pre-Hospital Trauma Life Support (PHTLS). Some of the requests were for non-traumatic conditions. For example, we created a series of rashes for specific scenarios in a multi-faceted field exercise at USU. Another example was a request from a civilian hospital asking for pressure ulcer tattoos. These were used to assist nursing students identify the different stages of ulcers patients may have.

\section{Formal Evaluation of Moulage Temporary Tattoos}

Initial uses of the moulage temporary tattoo quickly gained internal and external interest. We decided that in order to proceed further, a formal evaluation and user testing should be completed to assess the quality and usability of the tattoos by end users. It was our hope that these tattoos would save time and money, without diminishing the overall quality of moulage application. We applied for and received a Rapid Innovation Funding (RIF grant) though the Advanced Medical Technology Initiative (AAMTI). The initial grant covered a six-month study period but was extended to over a year. Data collection 
continued after the grant period ended due to continued interest and support from the VGHSC.

\section{Materials and Devices}

The first product decision involved selection of temporary tattoo paper. After assessing company products and customer reviews through an online search, we decided to test with three different companies: Silhouette America, Inc., Hemmi Papilio Supplies LLC, and World Paper. Internally, we tested all three brands of temporary tattoo paper during a training event and in stand-alone testing. All three had varying degrees of shine, wrinkle development, thickness, difficulty of use, and complexity of preparation. (Figure 7)

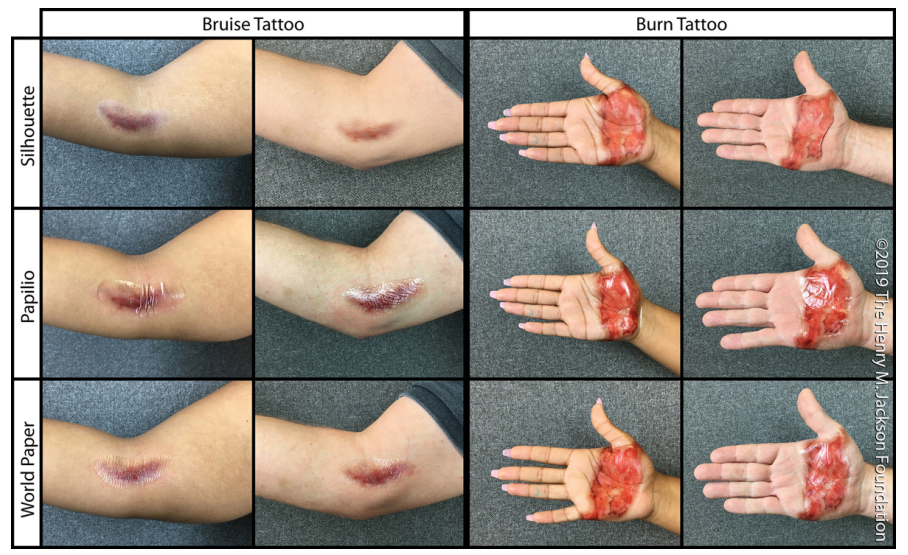

Figure 7. Three brands of tattoo paper (rows), each with the same illustration (bruise and burn) printed by the same printer, shown under similar lighting views. Male and female models, with different skin tones, were used (columns). Photo credit: Elizabeth Weissbrod (C2019 The Henry M. Jackson Foundation

We tested all three of the tattoo paper types with a standard desktop inkjet printer. The majority of commercially available tattoo papers are specified as inkjet compatible. Although some types of tattoo paper can be used with color laser printers, we decided to utilize papers designed for inkjet printing for accessibility reasons. For this project, we used the HP Envy 120 and 4520, and the Epson WorkForce ET-4550 EcoTank All-in-One inkjet printers. All of these printers are comparable in terms of cost, ink usage, and print resolution.

Our testing determined that the Silhouette Inc. temporary tattoo paper, with inkjet-printed illustrations, provided the thinnest, clearest, most flexible, and least shiny final product. The Silhouette brand temporary tattoo paper with inkjet printing was the only production method used when sending out samples for feedback.

Once the paper was chosen, we experimented with using a Silhouette CAMEO machine to automate the process of cutting out individual tattoos from the paper. However, due to technical difficulties with the equipment and software, the majority of the temporary tattoos were cut out by hand.

\section{Temporary Tattoo Illustrations}

In the course of this project, we created over 100 illustrations, depicting 15 anatomical structures, 11 different clinical pathologies, and 88 trauma wounds. During internal preliminary review and critique of the illustrations, attending physicians and surgeons provided informal feedback on the illustrations' accuracy concerning visual identification, size, and color. Test site users and subject matter experts (SMEs) provided further review and feedback, prompting adjustments to the illustrations.

One example of adjustments made after receiving initial feedback involved the appearance of some of the small-caliber gunshot wound (GSW) moulage tattoos. They were frequently mistaken by moulage artists and learners for cigarette burns. We made the following adjustments to the illustrations: made them slightly larger, gave an appearance of a hematoma forming under the skin around the injury site, and added a small dry blood trail. (Figure 8) Subsequent feedback from the revised moulage tattoo illustration provided no further concerns with the misidentification of small-caliber GSW moulage tattoos. This feedback and adjustment process allowed continual improvement of both original and revised illustrations.

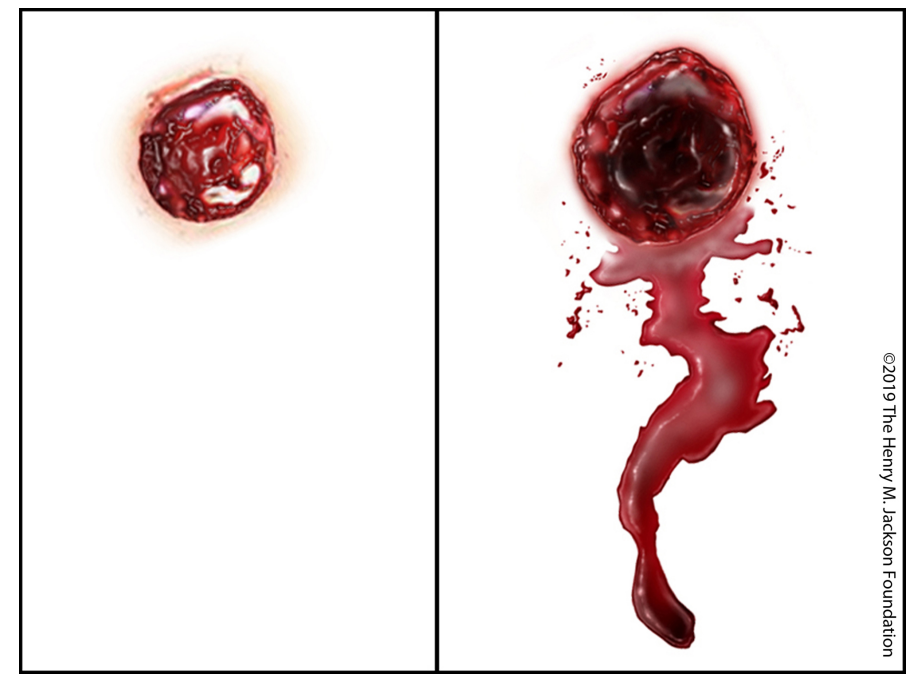

Figure 8. Original small caliber GSW illustration (left) and the adjusted small caliber GSW illustration (right) after feedback was received. (C)2018 The Henry M. Jackson Foundation

\section{Test Sites and Data Collection}

Temporary tattoo injury sets were sent initially to five military partners: at Womack Army Medical Center (Ft. Bragg, NC), the Army Medical Simulation and Training Center (MSTC) (Ft. Bragg, NC), Madigan Army Medical Center (Ft. Lewis, WA), as well as the team at the USU (Bethesda, MD). Each site received a custom packet with their set of moulage temporary tattoos. While the contents of the tattoo packets evolved through the project based on feedback, the following items were consistent in each packet: moulage temporary tattoo project flyer, envelopes of temporary tattoos by injury or case scenarios, and feedback surveys for learners, moulage artists, and standardized patients (SPs). (Figure 9) 


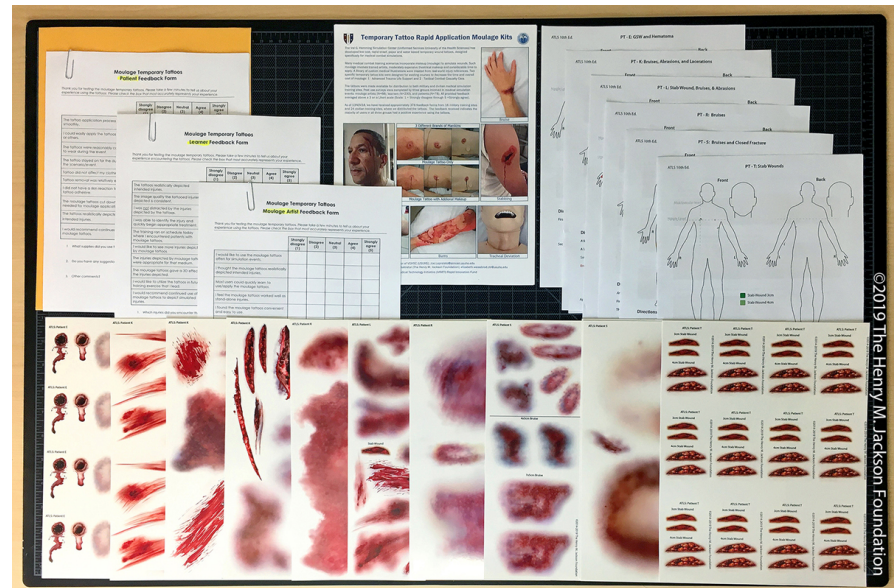

Figure 9. An example of what a typical tattoo packet contained for test sites. Photo credit: Elizabeth Weissbrod (C)2019 The Henry M. Jackson Foundation

We created different surveys for the three groups (learners, artists, and SPs), and each survey consisted of ten Likert scale questions. The scale ranged from " $1=$ strongly disagree" to " 5 = strongly agree." These were followed by two to three openended questions. We requested feedback on visual quality of the illustration, accuracy, and the usability and functionality of the temporary tattoos. Qualitative and quantitative data was collected to improve the overall process for each feedback group interacting with or utilizing the moulage temporary tattoos.

\section{Results}

There are five survey questions that inquire about the quality and realism of the injuries depicted by the moulage tattoo illustrations: moulage artists' feedback S2 and S7, learner feedback $S 1$ and $S 2$, and patient feedback $S 9$. ( $\mathrm{S}=$ Statement) All averaged a score of 4.2 or higher $(\max \mathrm{SD}=.88)$.

\section{Moulage Artist Feedback Results}

The moulage artists participants $(\mathrm{n}=71)$ were identified as those tasked with utilizing the tattoos and applying them to SPs or manikins for simulation scenarios. (Table 1a) Responses were tabulated and analyzed by the authors for use in making further improvements to the illustrations, product design, instructions, and user experience. The average score for 9 of the 10 questions were above a 4. The outlier is Q10, which averaged $3.9(\mathrm{SD}=.89)$. This correlates with comments provided in the qualitative feedback received.

\begin{tabular}{|l|c|c|c|}
\hline Moulage Artist Feedback Statements & Mean & SD & Range \\
\hline $\begin{array}{l}\text { S1 - I would like to use the moulage tattoos often for simulation } \\
\text { events }\end{array}$ & 4.5 & .8 & $2-5$ \\
\hline $\begin{array}{l}\text { S2 - I thought the moulage tattoos realistically depicted intended } \\
\text { injuries }\end{array}$ & 4.4 & .9 & $1-5$ \\
\hline S3 - Most users could quickly lean to use/apply the moulage tattoos & 4.7 & .5 & $3-5$ \\
\hline S4 - I feel the moulage tattoos worked well as stand-alone injuries. & 4.2 & 1 & $1-5$ \\
\hline S5 - I found the moulage tattoos convenient and easy to use. & 4.7 & .6 & $3-5$ \\
\hline $\begin{array}{l}\text { S6 - I feel the moulage tattoos cut down on time needed for moulage } \\
\text { application. }\end{array}$ & 4.6 & .7 & $2-5$ \\
\hline S7 - The image quality of the depicted injuries was consistent. & 4.4 & .8 & $1-5$ \\
\hline $\begin{array}{l}\text { S8 - I feel the moulage tattoos worked best when combined with } \\
\text { additional moulage makeup. }\end{array}$ & 4.4 & .8 & $2-5$ \\
\hline $\begin{array}{l}\text { S9 - The scenarios that utilized the moulage tattoos ran on schedule } \\
\text { today. }\end{array}$ & 4.6 & .6 & $3-5$ \\
\hline $\begin{array}{l}\text { S10 - I do not feel that training is necessary on how to apply the } \\
\text { tattoos before they are used during an event. }\end{array}$ & 4.0 & .9 & $2-5$ \\
\hline
\end{tabular}

Table 1a. Results of Likert scale feedback from moulage artists. $(S=$ Statement $)$

Qualitative feedback from moulage artists included wide range of comments. Of the 71 responses, 48 respondents $(67.6 \%)$ provided at least one written answer to the open-ended questions. (Table 1b) Despite difficulties encountered with initial application of the tattoos the feedback was positive and provided constructive recommendations. The average response to $\mathrm{S} 6$ was $4.6(\mathrm{SD}=.65)$, and 11 of the open-ended responses $(22.9 \%)$ indicated they saved time using the moulage temporary tattoos. The most common negative response was that with removing the top clear layer of the temporary tattoos $(n=7,9.8 \%)$. Users found this to be a difficult at times. One user shared a solution of using a piece of tape to assist with the removal. We tested this and began recommending this to other users in our written instructions/FAQs.

\begin{tabular}{|c|c|}
\hline Theme & Representative comments from Moulage Artists \\
\hline Time to apply & $\begin{array}{l}\text { - Makes things way faster; moulage victims can apply their own } \\
\text { wounds. } \\
\text { - Worked well for our course - cut down on prep time. } \\
\text { - Tattoos work and look great. Makes moulage easy and quick. } \\
\text { - The most positive finding for me is the time cut down on moulage } \\
\text { application! } \\
\text { - Quicker to apply and overall better results. }\end{array}$ \\
\hline Ease of application & $\begin{array}{l}\text { Excellent! Pt's seemed to like - less messy, easier application. } \\
\text { - Loved the easy application of the tattoo and now realistic they } \\
\text { looked at the start of exercise. } \\
\text { The tattoos are hard to get apart. The glue needs to be better. } \\
\text { - Great product! Make film easier to peel off. } \\
\text { It was very difficult to remove the clear plastic film cover. }\end{array}$ \\
\hline Realism & $\begin{array}{l}\text { Love these tattoos and looked surprisingly real. } \\
\text { The bruises were excellent. } \\
\text { The tattoos worked really well without additional moulage but the } \\
\text { additional simulated blood products really brought the realism. } \\
\text { Consider more color on the bruising tattoo especially on darker skin } \\
\text { tones. } \\
\text { The tattoos need some enhancing with additional moulage coverage } \\
\text { for a more realistic depiction. }\end{array}$ \\
\hline
\end{tabular}

Table 1b. Sample of qualitative feedback from moulage artists.

\section{Learner Feedback Results}

The learners who participated $(n=245)$ were those encountering the moulage temporary tattoos during a medical simulation course or scenario, regardless of specialty or skill level. (Table $2 \boldsymbol{a}$ ) Responses were tabulated and analyzed by the authors for use in making further improvements to the illustrations, educational quality feedback, and overall experience. The average score for all 10 questions was above a 4. The highest average score is S5, concerning whether the training ran on time when the tattoos were used, which was $4.49(\mathrm{SD}=.58)$. 


\begin{tabular}{|l|c|c|c|}
\hline Learner Feedback Statements & Mean & SD & Range \\
\hline S1 - The tattoos realistically depicted intended injuries. & 4.3 & .7 & $1-5$ \\
\hline S2 - The image quality the tattooed injuries depicted is consistent. & 4.4 & .7 & $2-5$ \\
\hline S3 - I was not distracted by the injuries depicted by the tattoos. & 4.1 & .9 & $1-5$ \\
\hline $\begin{array}{l}\text { S4 - I was able to identify the injury and quickly begin appropriate } \\
\text { treatment. }\end{array}$ & 4.3 & .8 & $2-5$ \\
\hline $\begin{array}{l}\text { S5 - The training ran on schedule today where I encountered patients with } \\
\text { moulage tattoos. }\end{array}$ & 4.5 & .6 & $2-5$ \\
\hline S6 - I would like to see more injuries depicted by moulage tattoos. & 4.3 & .8 & $2-5$ \\
\hline $\begin{array}{l}\text { S7 - The injuries depicted by moulage tattoos were appropriate for that } \\
\text { medium. }\end{array}$ & 4.4 & .6 & $2-5$ \\
\hline S8 - The moulage tattoos gave a 3D effect to the injuries depicted. & 4.0 & 1 & $1-5$ \\
\hline S9 - I would like to utilize the tattoos in future training exercise that I lead. & 4.3 & .7 & $1-5$ \\
\hline $\begin{array}{l}\text { S10 - I would recommend continued use of moulage tattoos to depict } \\
\text { simulated injuries. }\end{array}$ & 4.5 & .7 & $1-5$ \\
\hline
\end{tabular}

Table 2a. Results of Likert scale feedback from learners. ( $S=$ Statement)

The open-ended questions were less likely to be completed by the learners in this study. Only 71 (28\%) of learners provided open ended feedback. (Table $2 \boldsymbol{b}$ ) Of the feedback received $35 \%$ of comments were positive, $25 \%$ were negative, and $40 \%$ were neutral or applied to the medical education course operations rather than the moulage temporary tattoos. The most common negative comment related to the $2 \mathrm{D}$ aspect of the moulage temporary tattoos. They do not have any $3 \mathrm{D}$, or tactile, feel to them.

\begin{tabular}{|l|l|}
\hline Theme & Representative comments from Learners \\
\hline Realism/Image Quality & $\begin{array}{l}\text { Good depiction of injury. } \\
\text { Excellent training product. }\end{array}$ \\
& $\begin{array}{l}\text { Bruises 50/50. Some great, others not. Make bruise's consistently } \\
\text { darker \& more colorful, so they show up on skin better. }\end{array}$ \\
\hline Ease of Identification & $\begin{array}{l}\text { They are great for identifying injuries on actors. } \\
\text { Ithink more colorful or 'over-done' images would help students see } \\
\text { them. }\end{array}$ \\
& $\begin{array}{l}\text { When looking for wound, I feel for entry/exit wounds. There was no } \\
\text { way of feeling that type of injury. }\end{array}$ \\
\hline
\end{tabular}

Table 2b. Sample of qualitative feedback from learners.

The SPs who participated $(n=87)$ were those who had the moulage temporary tattoos applied to their skin for their role as a patient that learners would treat during a medical simulation course or scenario. (Table 3a) Responses were tabulated and analyzed by the authors for use in making further improvements to the illustrations, ease of application/use, durability, and overall experience of wearing the moulage temporary tattoos. The average score for all 10 questions was above a 4 . The highest average score is $\mathrm{S} 3$, concerning the durability of the tattoo for the length of time needed to wear, which was $4.84(\mathrm{SD}=.39)$.

\begin{tabular}{|l|c|c|c|}
\hline Patient Feedback Statements & Mean & SD & Range \\
\hline S1 - The tattoo application process went smoothly. & 4.8 & .4 & $4-5$ \\
\hline S2 - I could easily apply the tattoos to myself or others. & 4.6 & .7 & $2-5$ \\
\hline S3 - The tattoos were reasonably comfortable to wear during the event. & 4.8 & .7 & $3-5$ \\
\hline S4 - The tattoo stayed on for the duration of the scenario/event. & 4.8 & .5 & $2-5$ \\
\hline S5 - Tattoo did not affect my clothing. & 4.8 & .6 & $1-5$ \\
\hline S6 - Tattoo removal was relatively easily. & 4.0 & .9 & $2-5$ \\
\hline S7 - I did not have a skin reaction to the tattoo adhesive. & 4.8 & .5 & $2-5$ \\
\hline S8 - The moulage tattoos cut down on time needed for moulage application. & 4.7 & .6 & $2-5$ \\
\hline S9 - The tattoos realistically depicted intended injuries. & 4.6 & .7 & $3-5$ \\
\hline S10 - I would recommend continued use of moulage tattoos. & 4.7 & .5 & $3-5$ \\
\hline
\end{tabular}

Table 3a. Results of Likert scale feedback from patients. ( $S=$ Statement)
The SP qualitative feedback included open ended questions regarding the removal and improvement of the overall experience wearing the tattoos. Of the 87 responses, 76 (87\%) provided at least some feedback. (Table $3 \boldsymbol{b}$ ) The majority of these comments were answers to how SPs removed the moulage temporary tattoo(s). Twenty-six of the SPs indicated that they used only soap and water to remove them. Other methods listed for removing them included: spirit gum remover, make-up adhesive remover, baby/olive oil, facial wipes, vinegar, eye make-up remover, alcohol pads, and shaving cream.

\begin{tabular}{|c|c|}
\hline Theme & Representative comments from Patients \\
\hline Time to Apply & $\begin{array}{l}\text { - Great training, tattoos went on very smoothly and look realistic. } \\
\text { - Speeds up process. }\end{array}$ \\
\hline Realism & $\begin{array}{l}\text { - Very cool, realistic-looking, \& fast! } \\
\text { - } \text { Some tattoos were more realistic than others. } \\
\text { Perhaps even better if used in conjunction with make-up products to } \\
\text { produce enhanced 3d effect. }\end{array}$ \\
\hline Ease of Removal & - Came off easier than traditional moulage! \\
\hline
\end{tabular}

Table 3b. Sample of qualitative feedback from patients.

Since 2016 we have received over 300 requests for moulage temporary tattoos. These requests came from 17 military training sites and 32 civilian training sites. The scope of location testing sites expanded rapidly from the initial 5 military partner sites. Additional sites were added by word of mouth and promotion of the project (e.g. conference booth, talks, presentations, courses, etc.). In total 49 sites received tattoo packets. These sites included 17 military $(34.6 \%)$ and 32 civilian (65.3\%) simulation centers all over the United States (total 43, from 20 states and the District of Columbia) and at international sites (total 6, 4 continents: Europe,

Australia/Oceania, Asia, and Africa).

Additionally, we tracked how frequently each individual tattoo illustrations and ATLS patient case tattoos were requested. For general tattoo (combining all individual anatomical, clinical, and trauma illustrations) inquires, we found that burns $(\mathrm{n}=22)$, bruises $(n=21)$, and lacerations $(n=20)$ were the most requested. Of the 21 available ATLS patient cases, the top 5 requested cases, in order, were patients $\mathrm{E}(\mathrm{n}=23), \mathrm{L}(\mathrm{n}=22)$, and I $(\mathrm{n}=19)$.

\section{Discussion}

We designed moulage temporary tattoos to assist and ease the implementation of, and participation in, medical simulation education courses and events. Field testing the product in many different arenas and gathering feedback from all personnel involved allowed us to make needed adjustments as the project progressed. The tattoos were positively received, and there is a demand for a rapid application moulage solution.

As the use of simulation continues to expand within the MHS, funding and trained personnel are a constant need (Polk et al. 2018; Dorlac, Bishop, and Dorlac 2014). Some training sites have trained moulage artists on staff. These staff members are specially trained in how to create and apply moulage. Other sites do not have personnel trained in moulage application, but instead use other staff who are assigned moulage as an extra 
duty. Extra duty moulage staff may be non-medical personnel who are unfamiliar with medical terminology and do not understand basic anatomy. This is not ideal, because improper or inadequate moulage application can be detrimental to the effectiveness of the training (Mills et al. 2018; Petersen et al. 2017; Stokes-Parish, Duvivier, and Jolly 2017).

With limited funds and personnel for medical simulation, increasingly compressed course and training timelines, and the rapid expansion of simulation training throughout the military, there is a need to streamline the moulage application process. Our library of illustrations, that when printed on commercially available water-activated temporary tattoo media, can easily simulate many combat wounds. The use of temporary tattoos is a validated method for applying rapid application moulage and is comparable to more traditional moulage techniques (Pettitt 2017).

\section{Knowledge of Temporary Tattoo Application}

An unexpected finding from the samples sent to the training sites indicated most users are unfamiliar with how to apply a temporary tattoo. This issue was partially resolved after we created printed directions and a tattoo application video and sent them to each end user. However, this did not completely resolve the issue. Application instructions were not always communicated from the person receiving the tattoo packet to the personnel applying the tattoos. Confusion concerning tattoo application can diminish the use and overall impact of the tattoos among artists, learners, and SPs. To ensure that all end users had instructions we included printed instructions in each envelope of temporary tattoos included in the mailed packets.

\section{Future Directions and Commercialization}

The intent of this project was to create a tool for improving the speed, cost (monetary and personnel), and quality of moulage. We recognize that moulage temporary tattoos are physically limited to their 2D nature. While traditional techniques can be added to provide depth and texture it would be ideal to create
$3 \mathrm{D}$ temporary tattoos. The technology around $3 \mathrm{D}$ printing is rapidly expanding and this manufacturing process may be a solution to creating cost effective moulage prosthetics. Augmented (AR) and virtual reality (VR) could easily be incorporated with the moulage temporary tattoos. This technology may not be appropriate for real time training but could be ideal for teaching in a classroom setting. Utilizing the tattoos as digital markers, mobile device applications (app) can use them to retrieve additional information to further expand the knowledge of learners. For example, using a mobile (e.g. phone or tablet) or wearable device (e.g. AR or VR headsets), a user could scan a tattoo using the device camera, and be provided with additional teaching tools (e.g. animation, text, audio, photographs, case studies, references). Assessment components could also be built into the app, either pre- or postcourse and provide data for validation purposes. An example of this could involve using an interactive pre-course testing app assessing a learner's current knowledge of how to treat a specific injury prior to attending a course. Using the same app, the learners could then take a post course test to assess knowledge gained during a course. Future tests could be push out using the app to assess skill/knowledge attrition.

Throughout this project, we received many inquiries regarding where the moulage temporary tattoos could be purchased and how much the moulage temporary tattoos cost. We are currently working to establish an avenue for the commercialization. Through the relationship with HJF Technology Transfer Office, and potential business partners, we are finalizing a Cooperative Research and Development Agreement (CRADA) that will allow the sharing of the product presented in this paper. A license agreement has been fully executed, including potential business plans for the sale and distribution of the tattoos. It is our hope that these moulage temporary tattoos will be available for purchase in the near future.

\section{Acknowledgements}

Initial funding support for this study was provided though an AMEDD Advanced Medical Technology Initiative (AAMTI) Rapid Innovation Funding (RIF) grant. AAMTI is a component of the U.S. Army Medical Research and Materiel Command (USAMRMC) at the Telemedicine and Advanced Technology Research Center (TATRC), in Fort Detrick, MD.

Continued support of the project was provided by the Val G. Hemming Simulation Center (VGHSC) of the Uniformed Services University of the Health Sciences (USUHS) under the direction of Dr. Joseph Lopreiato (Associate Dean for Simulation Education), Dr. Mark Bowyer (Director of Surgical Simulation), Ms. Anita Springs (Chief of Staff), and all of the excellent staff at the VGHSC.

Assistance related to the commercialization of the moulage tattoos was provided by Mark G. Scher, Ph.D. (Chief
Technology Transfer Officer), at the Henry M. Jackson Foundation for the Advancement of Military Medicine.

\section{References}

Deering, Shad, Taylor Sawyer, Jeffrey Mikita, Douglas Maurer, and Bernard J. Roth. 2012. The central simulation committee (CSC): A model for centralization and standardization of simulation-based medical education in the U.S. Army healthcare system. Military Medicine 177 (7):82935 .

Dorlac, Warren C., Jonathan M. Bishop, and Gina R. Dorlac. "Use of simulation and military medical training: 2014." Worldwide military-medicine.com. September 30, 2014. https://military-medicine.com/article/3124-use-of-simulationmilitary-medical-training-2014.html. 
Goolsby, Craig, and Shad Deering. 2013. Hybrid simulation during military medical student field training--a novel curriculum. Military Medicine 178 (7):742-5.

Gormley, Gerry, Allison Menary, Brooke Layard, Nigel Hart, and Collette McCourt. 2013. Temporary tattoos: A novel OSCE assessment tool. The Clinical Teacher 10 (4):251-7.

Howard, Sheri. "Increasing fidelity and realism in simulation." Lippincott Nursing Education Blog, September 19, 2019, http://nursingeducation.lww.com/blog.entry.html/2018/09/19/i ncreasing_fidelity-zEj0.html

McGaghie, William C., S. Barry Issenberg, Elaine R. Cohen, Jeffrey H. Barsuk, and Diane B. Wayne. 2011. Does simulation-based medical education with deliberate practice yield better results than traditional clinical education? A metaanalytic comparative review of the evidence. Academic Medicine 86 (6):706-11.

Meguerdichian, David A., Jason D. Heiner, and Bradley N. Younggren. 2012. Emergency medicine simulation: A resident's perspective. Annals of Emergency Medicine 60 (1):121-6.

Merica, Bobbie. 2012. To the moulage designer. In Medical moulage: How to make your simulations come alive. Philadelphia, PA: F.A. Davis.

Mills, Brennan W., Alecka K. Miles, Tina Phan, Peggy M. C. Dykstra, Sara S. Hansen, Andrew S. Walsh, David N. Reid, and Claire Langdon. 2018. Investigating the extent realistic moulage impacts on immersion and performance among undergraduate paramedicine students in a simulation-based trauma scenario: A pilot study. Simulation in Healthcare: The Journal of the Society for Simulation in Healthcare 13 (5):331-340.

Petersen, Christopher, Stephen C. Rush, Isabelle Gallo, Bryan Dalere, Brian Staak, Litt Moore, Win Kerr, Matthew Chandler, and Will Smith. 2017. Optimization of simulation and moulage in military-related medical training. Journal of Special Operations Medicine 17 (3):74-80.

Pettitt, M. Beth H. 2017. Assessment of tattoo and silicone wounds in terms of time of treatment and perceived treatment quality, $\mathrm{PhD}$ diss., College of Engineering and Computer Science, University of Central Florida. http://purl.fcla.edu/fcla/etd/CFE0006904.

Polk, Travis M., Joy Greer, John Alex, Rebecca Kiser, Kim Gunzelman, Carl Petersen, and Michael Spooner. 2018. Simulation training for operational medicine providers (STOMP): Design and implementation of a novel comprehensive skills-based curriculum for military general medical officers. Military Medicine 183 (suppl_1):40-46.

Stokes-Parish, Jessica B., Robbert Duvivier, and Brian Jolly. 2017. Does appearance matter? Current issues and formulation of a research agenda for moulage in simulation. Simulation in
Healthcare: The Journal of the Society for Simulation in Healthcare 12 (1):47-50.

Swan, Nanci A. 2013. Burn moulage made easy (and cheap). Journal of Burn Care \& Research 34 (4):e215-20.

\section{Authors}

Elizabeth N. Weissbrod, MA, CMI, is a Senior Medical Illustrator for the Henry M. Jackson Foundation for the Advancement of Military Medicine at the Val G. Hemming Simulation Center of the Uniformed Services University. She creates content for military medical education in a wide range of medium and fields from 3D animation, traditional illustration, digital 2D artwork, medical moulage, 3D printing, mold making and casting, and prototyping simulators. Elizabeth.Weissbrod.ctr@simcen.usuhs.edu

Joseph O. Lopreiato, MD, MPH, FAAP, CHSE-A, is currently the Associate Dean for Simulation Education and Professor of Pediatrics, Medicine and Nursing at the Uniformed Services University of the Health Sciences in Bethesda, MD. He is the medical director of the Val G. Hemming Simulation Center, a multidisciplinary learning laboratory serving students across the continuum of medicine. Joe.Lopreiato@simcen.usuhs.edu

Mark W. Bowyer, MD, FACS, DMCC, FRCS (Glasg), is the Ben Eiseman Professor of Surgery and Chief of the Division of Trauma and Combat Surgery in the Department of Surgery, Uniformed Services University and the Walter Reed National Military Medical Center, as well as Director of Surgical Simulation at the Val G. Hemming Simulation Center. He is responsible for creating and validating robust realistic curricula that incorporate best in class educational tools to include all aspects of simulation, medical illustration, animations, and virtual and augmented reality to train health care providers around the world to care for the victims of trauma.Mark.Bowyer@usuhs.edu

Danielle A. Simms, is an Infused Solutions contractor, at the Val G. Hemming Simulation Center. She assists in maintaining and improving all office operations. She is responsible not only for general office and clerical support tasks but also in providing feedback and production design assistance. Externally, she has been creating and executing custom designs for over 3 years and applies that knowledge to projects supporting the staff, faculty, and students, directly contributing to the success of the Uniformed Services University mission. Danielle.Simms.ctr@simcen.usuhs.edu

Eric M. Singdahlsen, MFA, is an HJF contractor at the Val G. Hemming Simulation Center. Mr. Singdahlsen manages the Hybrid Simulations Laboratory and serves as liaison for external clients. He is responsible for supporting curricula related to life-saving, resuscitation, first response, disaster response, mass-casualty and pre-deployment training. He has been practicing and teaching moulage since 2007 . 
Mr. Singdahlsen has been actively working in simulationbased training for over 17 years in the Washington, D.C region. Eric.Singdahlsen.ctr@simcen.usuhs.edu

\section{Licensing}

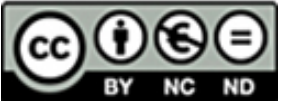

The authors have chosen to license this content under a Creative Commons Attribution, NonCommercial, No Derivatives 4.0 International License.

\section{Conflict of Interest Statement}

The Journal of Biocommunication Management Board and Editors believe that transparency in academic research is essential. Our $J B C$ authors are now required to disclose any possible conflict of interest when submitting a paper.

In accordance with the Journal of Biocommunication's editorial policy, no potential conflict of interest has been reported and declared by the author(s). 